\title{
A Thermal Improvement Technique for the Phase Windings of Electrical Machines
}

\author{
Michael Galea, Chris Gerada, Member IEEE, Tsarafidy Raminosoa, Member IEEE \\ and Patrick Wheeler, Member IEEE
}

\begin{abstract}
In electrical machines, a higher torque/force density can usually be achieved by increasing the current density in the windings. However, the resulting increase in copper losses leads to higher temperatures in the coils, especially in the centre of the slots where the thermal resistance to the ambient/cooling surfaces is highest. In this paper a novel, simple technique is presented in which a higher thermal conductivity path between the centre of the slot and the cooling arrangement is created, thus increasing the heat flow away from the slot centre. A lumped parameter thermal model is presented and used along with finite element analysis to investigate the effectiveness of the proposed technique. The lumped parameter model is also used for optimizing the high conductivity path for maximum air-gap shear stress and to obtain a compromise between the reduced slot area and the improved temperature distribution. Experimental validation is then presented to compare the predicted results with the measured results on a purposely built instrumented set-up.
\end{abstract}

Index Terms - Permanent magnet machines, electrical machine windings, high current density, thermal improvements.

\section{INTRODUCTION}

$\mathrm{I}_{\mathrm{e}}^{\mathrm{N}}$ $\mathrm{N}$ recent years the need for improvement in terms of size, efficiency and costs of electrical machines has become a main issue which electrical machine designers have to consider through all the design stages [1]. This is most significantly apparent in high performance environments such as the aerospace industry, where torque/force density, fault tolerance and reliability are of vital importance [2], [3].

Despite the vastness of the range of electrical machines available today, in general all machines are subject to the constraints imposed by the materials (copper, insulation, soft and hard magnetic materials) from which their main components are constructed [4].

These constraints can be considered to fall into two main categories, namely the electro-magnetic limit and the thermal limit. These two limits quantify what force/torque can be obtained from a particular machine. The electro-magnetic limit is set by the soft magnetic material saturation point and

Manuscript received April 30, 2011.

This work was supported by the "EU FP7 funding via the Clean Sky JTI Systems for Green Operations ITD".

Michael Galea (eexmg1@ nottingham.ac.uk, phone: 0044-115-846-8840), Chris Gerada (chris.gerada@nottingham.ac.uk) and Patrick Wheeler (pat.wheeler@nottingham.ac.uk) are with the School of Electrical and Electronic Engineering, University of Nottingham, Nottingham, NG7 2RD, UK). Tsarafidy Raminosoa (t.raminosoa@ieee.org) was with the University of Nottingham until 2011. He is now with GE Global Research, Niskayuna, US. possibly by the maximum armature reaction field so as not to demagnetize the permanent magnets (PM). The thermal limit which is related to the cooling arrangement sets the maximum current density at which a machine can operate safely at. This typically lies below the electro-magnetic limit in steady state and hence extending this thermal limit by adequate cooling automatically results in machines that can operate at higher current densities, thus achieving a higher torque/force for the same machine mass.

Natural cooling of electrical machines [5], [6] has traditionally been enhanced by the use of fins and ducts on the outer housing [7], [8] so as to improve convection and radiation heat transfer. Forced air cooling methods such as [9] and [10], usually result in better cooling at the cost of extra complexity and extra components. A high performance method of cooling involves the use of liquids [11] - [13], especially in environments where a cooling circuit is already present.

A common and convenient way to apply fluid cooling is through a stator jacket. This avoids rotating seals and potential viscous drag. This type of arrangement works reasonably well for machines with relatively small rotor losses such as with permanent magnet brushless motors. This is however a non optimal way of heat removal as a considerable temperature gradient exists between the outer stator surface and the winding hot-spots in the centre of the slots and in the endwindings. To this end, direct cooling solutions have been adopted such as oil-spray cooling [14] and directly cooled conductors [15]. However, the complexity of such arrangements is only justifiable in large machines. This paper will present an innovative way to provide an effective low thermal resistance path between the winding hot-spots and the cooling stator jacket.

In general, temperature builds up mostly in the centre of the coils as this is the point where the thermal resistance to the ambient/cooling fluid is highest. For low to medium speed applications, the most significant loss component is the winding copper loss [16]. For a given machine geometry and number of conductor turns, the number of slots and the slot geometry have a significant impact on the maximum linear current loading and torque achievable. Typically, lower slot numbers allow better slot fill factor but increase the thermal resistance between the coil hot-spot and the soft magnetic material. This paper will investigate the trade-off between the benefit of having a high thermal conductivity between the coil 
centre and the cooling medium after the insertion of a lowresistance heat path in the slot of a fractional slot machine and the resulting reduced winding area. This paper will show the added benefits of such an arrangement.

The objective of this paper is thus to present a simple technique by which the temperature distribution in the slot area of electrical machines can be improved. The work reported in this document is based on the water cooled, 12slot/10-pole, double layer wound, tubular linear permanent magnet (TLPM) machine, presented in [13]. Fig.1 shows the general structure of the TLPM machine under consideration.

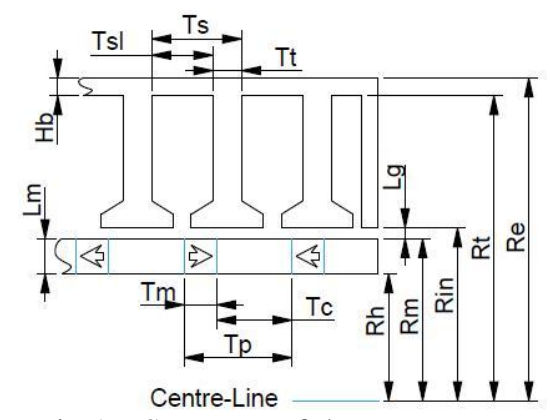

Fig.1 Structure of the TLPM motor

\section{CONCEPT OF THE THERMAL IMPROVEMENT TECHNIQUE}

Fig. 2a shows an image of one slot of the TLPM motor, where the total copper area depends on the slot fill factor $K_{\text {fill }}$, defined as the net copper area in the slot divided by the total slot window. This can generally reach high values $(>0.6)$ for pre-formed coils [17]. In between the individual conductors, there is usually some type of varnish, resin or potting compound to provide mechanical integrity, adequate insulation, an improved thermal conductivity and protection against ingress of foreign particles. A slot wall liner is also often required to provide insulation to ground unless suitably thick conductor wire insulation is adopted.

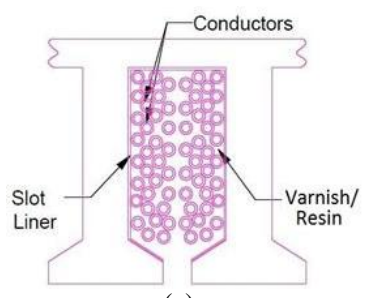

(a)

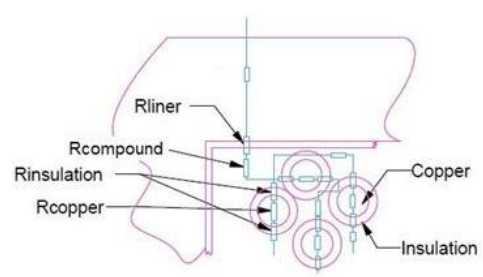

(b)
Fig.2 The slot area

As illustrated in the representative thermal resistance network of Fig.2b, the effective thermal resistance to the conductor copper losses can be quite significant, especially in the central slot section which leads to winding hot-spots. The equivalent thermal conductivity of the whole composite slot area $k_{e q}$, is relatively poor compared to that of copper $k_{c u}$. However, by inserting a heat flow path (HP) in the slot such as shown in Fig.3a, the thermal resistance of the dominant heat conduction path is reduced. This achieves an enhanced thermal conductivity from the centre of the slot towards the outer walls, which should result in a better distribution of heat over the slot area and also in an overall reduction of peak hotspot temperature [13].

It is important to note that whilst for most electric machines the main limiting hot-spots are usually located in the endwindings [18] [19], for tubular machines (with no endwindings) the winding hot-spots in the slots practically define the thermal limit of the machine and thus the maximum allowable current density and the resulting maximum output force. However, a HP could technically be also adopted in rotational machines with end-windings, where it would be more practical to adopt for pre-formed coil, concentrated wound machines. This would help provide a better thermal path to the winding losses and although the hot-spot would still be in the end-winding this would be reduced with respect to the case of not adopting a low resistance thermal path.

The negative implications of introducing this path are the smaller winding window area, resulting in a higher winding resistance and consequently higher copper losses for the same electrical loading at a given temperature and any additional eddy current losses in the HP itself. The material to be used for the heat flow path ideally needs to have a high thermal conductivity and a low effective electrical conductivity. This is achieved through segmentation. Fig.3b shows the basic structure of the initial proposed design of the HP.

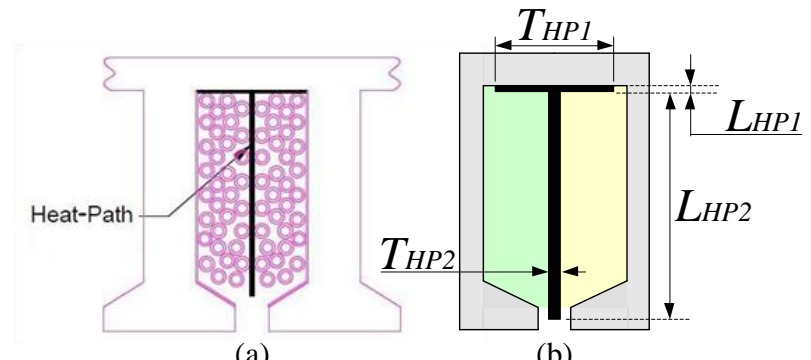

(a)

(b)

Fig.3 Slot with HP and structure of the HP

The initial design shown above is proposed taking into account the geometry of the TLPM motor presented in [13]. As shown further on, the narrow, deep nature of the slots of this particular machine results in the HP having a large effect on the thermal performance of the machine due to the large distance of the hot-spot from the back iron. For machines with a considerable slot width and small slot depth, the effect of the HP will be less significant if the same design as shown in Fig. 3b is kept. Therefore, for configurations with large slot width to slot depth aspect ratios it might be appropriate to consider an alternative design such as the multi-finned HP shape shown in Fig.4.

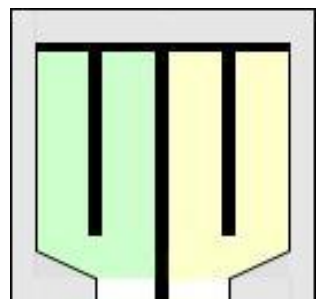

Fig.4 Proposed HP for wide, shallow slots 


\section{MODELING}

In this section, one slot-tooth section of the TLPM motor is modeled, assuming a symmetric temperature distribution along the machine. A simplified lumped parameter network model is first presented, able to quickly estimate a rough temperature distribution within the machine. This is intended to be used at the design stage where many geometric iterations are made. A finite element (FE) model is also constructed for comparison and to justify some of the assumptions made.

\section{A. Lumped Parameter Network}

Using the traditional lumped parameter networks approach [20], [21] the slot is modeled as a number of thermal resistances from the slot centre to the ambient/cooling agent. Assuming the predominant thermal dissipation in the machine is in the radial direction and assuming negligible iron losses then a slot pitch of the double layer TLPM motor can be modeled as shown in Fig.5, where $R_{1}-R_{12}$ are the thermal resistances, $R_{w a t}, R_{h c}$ and $R_{\text {tipa }}$ are the defining radii of the TLPM motor, $P_{c u}$ is the copper loss in one coil and $T_{w a t}$ is the cooling fluid temperature reference. The slot is longitudinally divided into three equal parts. For clarity, only the resistive elements are shown. Capacitors representing thermal masses can be easily added at each node if transient behavior needs to be evaluated. As a first approximation, the hot-spots are assumed to be at the central nodes at height $R_{h c}$ and $K_{\text {fill }}$ is assumed as 0.45 . A more accurate temperature distribution can be achieved simply by including more nodes in the network.

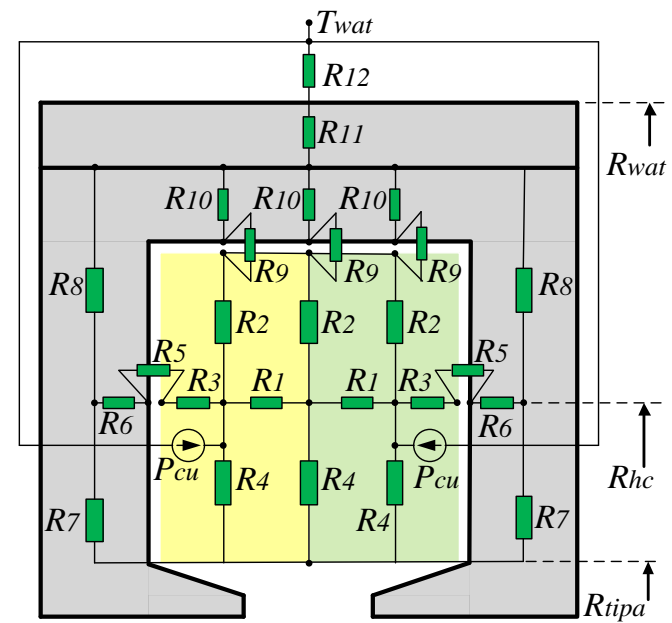

Fig.5 Lumped parameter network for one slot

Applying the basic equations for thermal resistance [20] to the model in Fig.5, the thermal resistances can be derived. These are given in (1)-(11) and (16) where $k_{F e}$ and $k_{A l}$ are the thermal conductivities of steel and aluminum respectively, whereas $k_{\text {lin }}$ and $T_{\text {lin }}$ are the thermal conductivity and thickness of the slot liner insulation.

$$
\begin{gathered}
R_{1}=\frac{T_{s l}}{3 \pi \times k_{e q} \times\left[\left(R_{t}-T_{\text {lin }}\right)^{2}-R_{\text {tipa }}^{2}\right]} \\
R_{2}=\frac{\ln \left(\left(R_{t}-T_{\text {lin }}\right) / R_{h c}\right)}{\frac{2 \pi}{3} \times k_{e q} \times T_{s l}}
\end{gathered}
$$

$$
\begin{aligned}
& R_{3}=R_{1} / 2 \\
& R_{4}=\frac{\ln \left(\frac{R_{h c}}{R_{\text {tipa }}}\right)}{\frac{2 \pi}{3} \times k_{e q} \times T_{s l}} \\
& R_{5}=\frac{T_{\text {lin }}}{k_{\text {lin }} \times \pi\left(R_{t}^{2}-R_{\text {tipa }}^{2}\right)} \\
& R_{6}=\frac{T_{t}}{2 \pi \times k_{F e} \times\left(R_{e}^{2}-R_{i n}^{2}\right)} \\
& R_{7}=\frac{\ln \left(R_{h c} / R_{i n}\right)}{\pi \times k_{F e} \times T_{t}} \\
& R_{8}=\frac{\ln \left(R_{e} / R_{h c}\right)}{\pi \times k_{F e} \times T_{t}} \\
& R_{9}=\frac{\ln \left(R_{t} /\left(R_{t}-T_{\text {lin }}\right)\right)}{\frac{2 \pi}{3} \times k_{\text {lin }} \times T_{s l}} \\
& R_{10}=\frac{\ln \left(R_{e} / R_{t}\right)}{\frac{2 \pi}{3} \times k_{F e} \times T_{s l}} \\
& R_{11}=\frac{\ln \left(R_{\text {wat }} / R_{e}\right)}{\pi \times k_{A l} \times T_{S}}
\end{aligned}
$$

The resistance $R_{12}$ is mainly dependent on the convective heat transfer coefficient $h_{\text {wat }}$ [11]. Fig.6 shows a crosssectional view along the axial length of the coolant ducts, where $P_{h}$ is the perimeter of the ducts that has contact with the coolant and $A_{h}$ is the hydraulic cross-sectional area of the coolant flow.

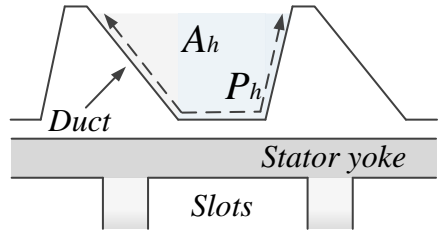

Fig.6 Coolant ducts

The hydraulic diameter $d_{h}$ of the water jacket is found from (12), then the Reynolds number $R_{e y}$ can be computed from (13), where $v_{s c}$ is the kinematic viscosity of water and $V_{w a t}$ is the velocity of the cooling fluid.

$$
\begin{aligned}
d_{h} & =\frac{4 A_{h}}{P_{h}} \\
R_{e y} & =\frac{d_{h} \times V_{w a t}}{v_{s c}}
\end{aligned}
$$

The Prundtl number $P_{r}$ of water at $20^{\circ} \mathrm{C}$ is 7.01. As stated in [11], considering that $P_{r} \geq 1.5$, then the Nusselt number $N_{u}$ of the system can be computed from (14) where $l_{\text {wat }}$ is the length along the ducts through which the cooling fluid flows. Finally, 
$h_{\text {wat }}$ can be calculated from (15), where $k_{\text {wat }}$ is the thermal conductivity of water, and $R_{12}$ is as described by (16).

$$
\begin{gathered}
N_{u}=0.012\left(R_{e y}^{0.87}-280\right) \times P_{r}^{0.4}\left(1+\sqrt[3]{\left(\frac{d_{h}}{l_{w a t}}\right)^{2}}\right) \\
h_{w a t}=\frac{k_{w a t} \times N_{u}}{d_{h}} \\
R_{12}=\frac{1}{2 \pi \times R_{w a t} \times T_{s} \times h_{w a t}}
\end{gathered}
$$

The equivalent thermal conductivity of the windings $k_{e q}$ is dependent on a number of components and their properties such as $K_{\text {fill }}$, the winding insulation, the impregnating compound etc. Assuming that the conductor insulation has the same thermal properties as the impregnation resin and that a good impregnation is achieved, then using an Area Weighted Average approach, $k_{e q}$ can be simplistically computed from (17) where $k_{\text {res }}$ is the equivalent thermal conductivity of the impregnating resin.

$$
k_{e q}=\frac{k_{c u} k_{r e s}}{\left(k_{r e s} K_{f i l l}\right)+\left(1-K_{f i l l}\right) k_{c u}}
$$

From the above, having a maximum permissible winding temperature $T_{\max }$, the maximum value of copper losses $P_{c u}$ for each coil can be found. Finally, the maximum value of the copper current density $J_{r m s}$ can be found from (18), where $\rho_{c u}$ is the resistivity of copper at a given winding temperature.

$$
P_{c u}=\pi \times T_{s l} R_{h c} K_{f i l l} \times \rho_{c u}\left(R_{t}-R_{\text {tipa }}\right) J_{r m s}^{2}
$$

\section{B. Lumped Parameter Network with Heat-Path}

The thermal improvement technique involves the insertion of a piece of thermal conductive material (the HP shown in Fig.3b) into the slot. The resulting lumped parameter network is shown in Fig.7, where if the material used for the HP has a thermal conductivity $k_{A l}$, then the thermal resistances are as described by (19)-(23). From (23) it can be noted that $R_{H P 3}$ represents the thickness $L_{H P 1}$ and also the liner at the slot wall.

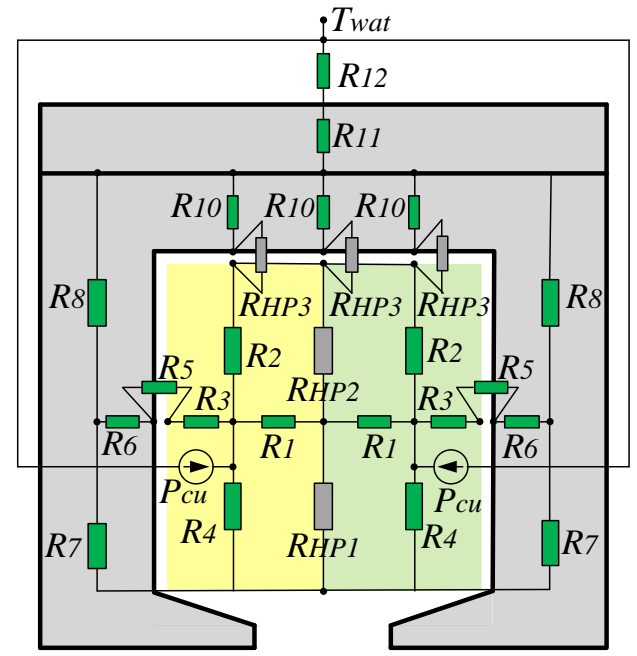

Fig.7 Lumped parameter network for one slot with HP

$$
\begin{gathered}
R_{1}=\frac{\left(2 T_{s l}-3 T_{H P 2}\right)}{6 \pi \times k_{e q} \times\left[\left(R_{t}-T_{\text {lin }}-L_{H P 1}\right)^{2}-R_{\text {tipa }}^{2}\right]} \\
R_{2}=\frac{\ln \left(\frac{\left(R_{t}-T_{\text {lin }}-L_{H P 1}\right)}{R_{h c}}\right)}{\frac{2 \pi}{3} \times k_{e q} \times T_{s l}} \\
R_{H P 1}=\frac{\ln \left(\frac{R_{h c}}{R_{t i p a}}\right)}{2 \pi \times k_{A l} \times T_{H P 2}} \\
R_{H P 3}=\frac{\ln \left(\frac{\left(R_{t}-T_{\text {lin }}-L_{H P 1}\right)}{2 \pi \times k_{h l} \times T_{H P 2}}\right)}{\frac{R_{H P 2}=}{\left(\frac{2 \pi}{3} \times k_{A l} \times T_{H P 1}\right.}+\frac{R_{t}-T_{l i n}}{\ln \left(\frac{2 \pi}{3} \times k_{\text {lin }} \times T_{s l}\right.}}
\end{gathered}
$$

Assuming a high thermal conductivity of the HP, then from Fig.7 it is clear that a low thermal resistance path has been created along the centre of the slot. The HP is practically acting as a thermal 'short-circuit', through which the heat generated by the copper losses is encouraged to flow towards the stator cooling arrangement. Using the same analysis as explained previously, it is again possible to calculate the temperatures at the different nodes in the thermal network, representing the different points in the slot. The maximum value of $J_{r m s}$ for a safe operating temperature can be found.

\section{Initial Tests and Comparisons}

In order to confirm the effectiveness of this technique some initial tests are done. Fig.8 compares the results obtained from the models of Fig.5 and Fig.7 when a HP with an initial design of $T_{H P 2} \approx 0.1 T_{s l}$, and $L_{H P 2}=\left(R_{t}-R_{\text {in }}\right)$ is considered. The material chosen is aluminum. The models are investigated considering the copper losses at steady state, based on a constant TLPM motor output generated thrust force (i.e. equal linear current loading). From Fig.8 it is immediately clear that the peak hot-spot temperature in the winding has decreased considerably $\left(\approx 110^{\circ} \mathrm{C}\right.$ compared to $\left.\approx 180^{\circ} \mathrm{C}\right)$, thus confirming the effectiveness of this technique in terms of peak slot temperature reduction.

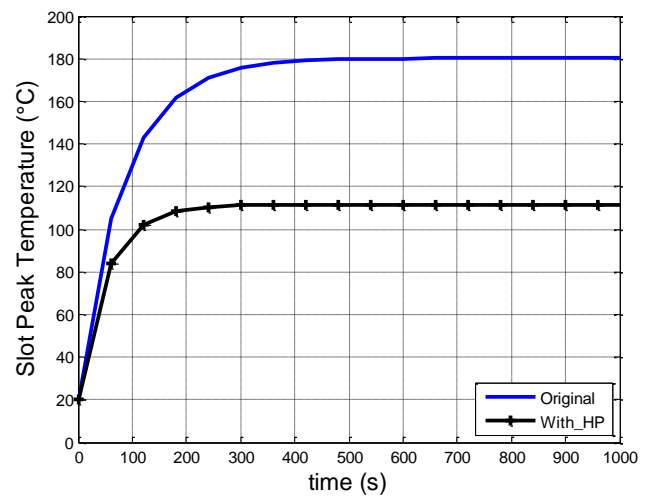

Fig.8 Initial lumped parameter model results 


\section{Finite Element Model}

A more accurate approach to thermal modeling of the slot area can be achieved using numerical methods. An electromagnetic/thermal FE software package is used to model the slot of the TLPM motor. The same conditions and assumptions as used to obtain the results of Fig. 8 are applied to the FE models. The slot area (assuming same $K_{\text {fil }}$ as above) is modeled as one piece of conducting material (copper) with $k_{e q}$ as calculated using (17). A thermal boundary dependant on $h_{\text {wat }}$ as derived from (15) and with the same initial temperature as above is applied at the ducts of the water jacket.
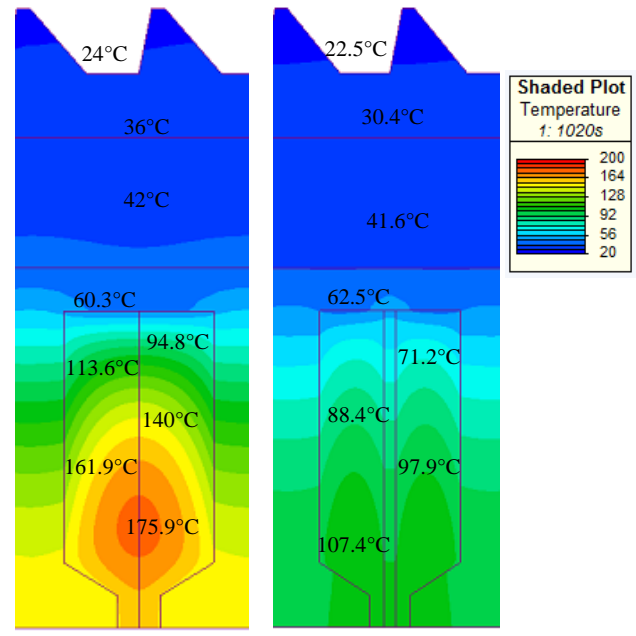

Fig.9 Slot temperature distributions from FE model

Fig.9 compares the slot temperature distribution for the model with and without the HP, at a steady state condition. It is worth noting that apart from the lower peak slot temperature and the more even temperature distribution, the temperature in the back iron and housing are also lower, when the HP is present. This reflects the lower total losses due to the reduced net winding temperature. Fig.10 compares the peak temperatures from the lumped parameter network models with those of the FE models. The results from both models show a reasonable similarity which validates the analytical model again confirming the effectiveness of the HP in the slot.

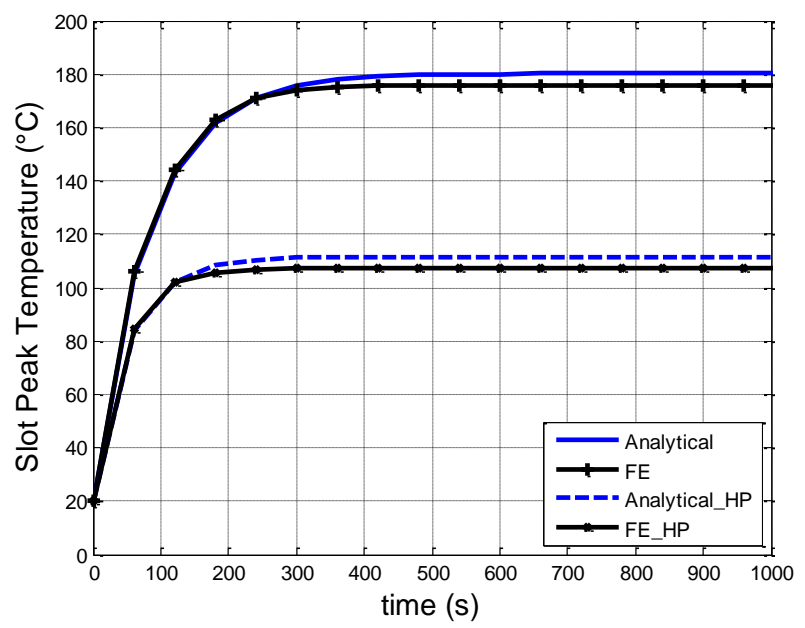

Fig.10 Comparing analytical with FE results

\section{DESIGN AND OPTIMIZATION}

Having confirmed that a thermal improvement does occur with the insertion of the HP in the slot then using a combination of both FE and analytical models, various designs of the shape and thickness of the HP are tested in an attempt to optimize to the most effective geometry. The main parameter to be optimized is the HP thickness $T_{H P 2}$ which results in a trade-off between the winding area available and the HP thermal resistance.

\section{A. Geometry and Dimensions}

1) The HP thickness $T_{H P 2}$

Considering the geometry of Fig.3b, the main parameter of interest for optimisation is $T_{H P 2}$. In general, the thicker the HP, the lower is its thermal resistance. However a thicker HP takes up more space, thus increasing the copper loss. An optimum value exists and is selected by an optimisation procedure. The FE model of the TLPM motor is tested for various values of $T_{H P 2}$. For each test, $J_{r m s}$ is adjusted to achieve a peak hot-spot temperature in the slot of $180^{\circ} \mathrm{C}$. Fig. 11 plots the TLPM motor generated output force and the copper losses for increasing values of the thickness of $T_{H P 2}$ (for $T_{s l}=11.35 \mathrm{~mm}$ ).

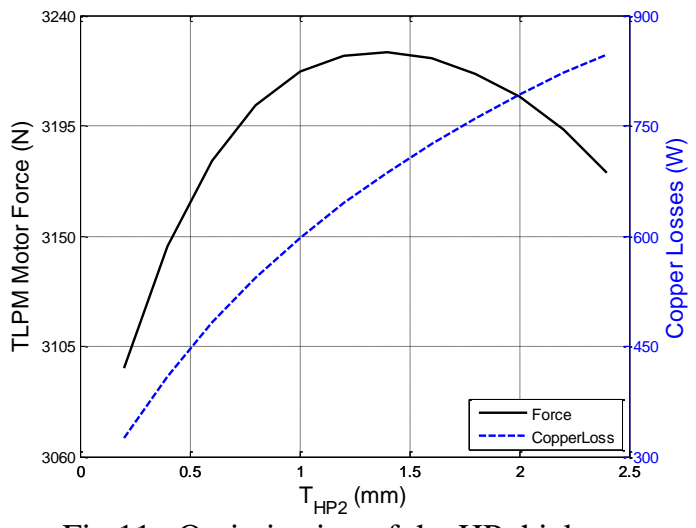

Fig.11 Optimization of the HP thickness

In Fig.11, it can be observed how up to the optimum $T_{H P 2}$ value of approximately $1.2 \mathrm{~mm}$, the generated TLPM motor force is increasing, because the thicker HP is permitting a higher $J_{r m s}$ to be used. After this value, the increasing copper losses due to the reducing copper area result in a reduction in the current density allowed for the $180^{\circ} \mathrm{C}$ maximum temperature constraint.

In an effort to understand the optimal HP thickness as a function of the slot width, a study of the relationship between the optimal $T_{H P 2}$ and $T_{S l}$ is conducted. The analytical model is used to find the optimum value of $T_{H P 2}$ that results in the maximum current loading possible whilst still observing the winding temperature limit, for different values of $T_{s l}$. Fig.12 shows the resulting relationship in a per-unit system, where the optimal slot width $T_{s l}$ as found in [13] and presented in Table I is taken as $1 \mathrm{pu}$. It can be observed how for relatively small slot width the optimal $T_{H P 2}$ exhibits a linear increase relative to $T_{s l}$. As the slot width increases (for the same slot height) the relative impact of the HP decreases and the "normal" heat transfer path through the conductors and resin to the back iron becomes more dominant. 
This relationship between $T_{H P 2}$ and $T_{s l}$, also has a direct effect on the maximum permissible current loading (and consequently air-gap shear stress) that can be used. Using the results of Fig.12, the respective current loadings are plotted in pu values in Fig.13, where the current loading is taken as $1 \mathrm{pu}$ when $T_{s l}=1 \mathrm{pu}$. It can be observed that as $T_{s l}$ increases, and for an optimum HP width, the maximum current loading achievable exhibits decay and does not remain constant. In essence this points to an alternative HP configuration along the lines of the one shown in Fig.4.

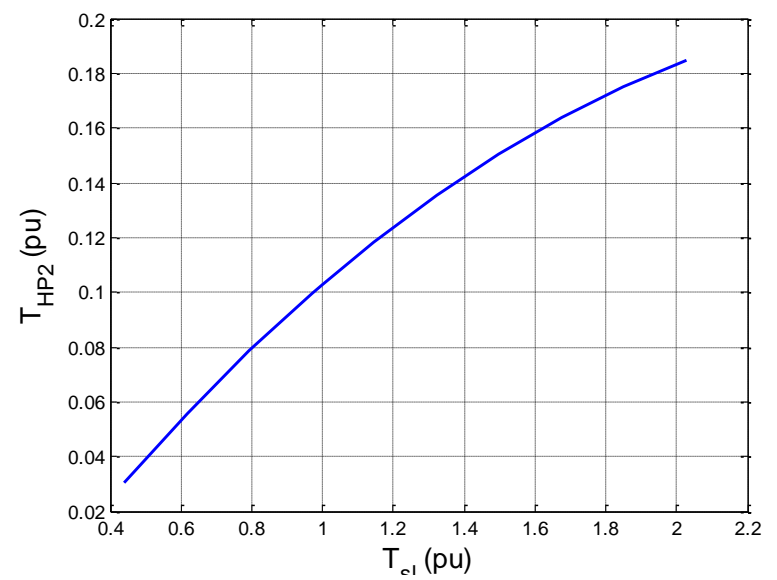

Fig.12 Optimum value of $T_{H P 2}^{c 1}$ for various slot widths in pu

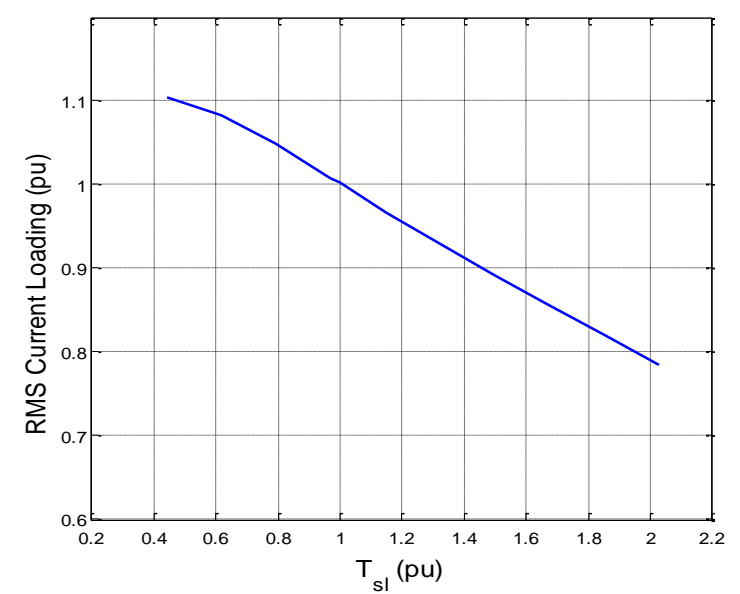

Fig.13 Maximum current loading for various slot widths

\section{2) The HP length $L_{H P 2}$}

It can be observed from Fig. 3 and Fig.7 that optimization of the HP length $L_{H P 2}$ resides in the fact that it need only be long enough to "thermally short-circuit" the point of the highest peak temperature with the stator back iron at $R_{t}$. Considering the slot temperature distribution shown in Fig.9, it is clear that the main hot-spot is located at approximately half way between $R_{h c}$ and $R_{\text {tipa }}$. Thus setting $L_{H P 2}$ to approximately $\frac{3}{4}\left(R_{t}-R_{\text {in }}\right)$, one can theoretically achieve the required thermal improvement whilst minimizing the loss of copper area. This however does not have any practical consequences as the pre-formed coil window would still have the same dimensions, irrespective of $L_{H P 2}$. The length $L_{H P 2}$ is thus taken as $\left(R_{t}-R_{\text {in }}\right)$, i.e. the whole slot depth.
3) The dimensions $T_{H P I}$ and $L_{H P I}$

As can be observed in Fig.9, theoretically the thickness $L_{H P I}$ and the span $T_{H P I}$ do not have any significant effect on the reduction of the dominant thermal resistance. But in practice one needs as much surface area as possible to be in contact with the inside of the slot wall at $R_{t}$, thus finite values of these two parameters need to be set. The main consideration here is to achieve maximum contact between the surface of the HP and the slot wall at $R_{t}$, whilst keeping the material volume to a minimum. By practical experiment, optimum values are found to be $T_{H P 1}=T_{s l}$ and $L_{H P 1} \approx \frac{1}{2} T_{H P 2}$, thus achieving a reliable contact area and overall robustness of the HP.

\section{B. Minimizing the HP losses}

A main concern regarding the solid nature of the HP inserted into the slot area is the resulting eddy currents induced in the HP itself. This is mostly relevant for the case of a tubular motor such as considered in this work, due to the fact that the HP ring shape necessary for a tubular motor, intrinsically creates a return path for any induced eddy currents. For the case of a radial machine, where the HP would take the shape of a "T-section", no closed loop would be present, resulting in minimum losses.

For a ring shaped HP such as shown in Fig.15, the eddy current losses are mainly generated due to the same flux that links the windings, which is made up of the magnet flux and the armature flux. These losses can be described by (24) where $\varphi_{H P}$ is the flux linked by the HP, $\omega_{e}$ is the electrical frequency, $\rho_{A l}$ is the electrical resistivity of the HP material and $L_{H P}$ and $A_{H P}$ are the mean circumference and the cross-sectional area of the HP respectively.

$$
P_{e d}=\frac{A_{H P}\left(\varphi_{H P} \times \omega_{e}\right)^{2}}{\rho_{A L} \times L_{H P}}
$$

Considering the same conditions and assumptions taken to achieve the results of Fig.8 and Fig.9, an electromagnetic FE model is used to investigate the effects of these eddy currents. Fig. 14 compares the eddy losses induced in the HP for two synchronous frequencies at full load.

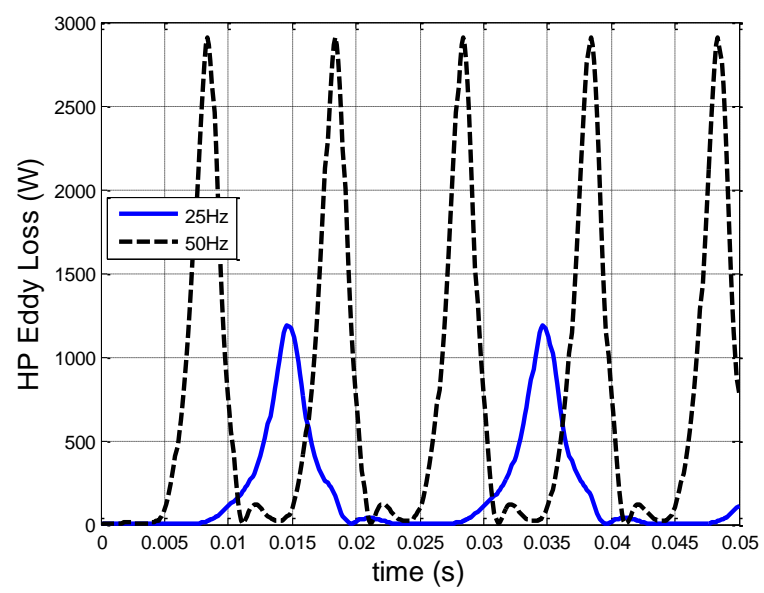

Fig.14 Eddy losses in the HP at full load 
By comparison to the copper loss shown in Fig.11, it is immediately clear that the loss in the HP due to eddy currents is considerably high, especially for higher synchronous frequencies. For practical terms, this would almost completely nullify the thermal advantage gained by the insertion of the HP. This loss can however be drastically reduced by 'opening' the conductive path travelled by these eddy currents. This is achieved by the use of slitting in the HPs. An investigation on this approach is conducted. A single slot setup is modeled in 3D for different slitting configurations and the results compared. Fig.15 shows the HPs of these models and highlights how the HPs are modified. For reasons of clarity and visualization, the slits are shown much larger than what is required in practice.

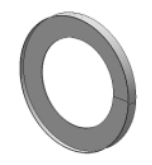

HP1

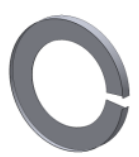

HP2

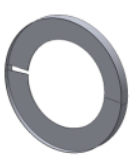

HP3
Fig.15 Solutions for reduction of eddy current loss

The first model HP1 shows the HP as a solid ring of aluminum whilst HP2 incorporates slitting. The model HP3 has only a partial cut, i.e. the slit does not open circuit the eddy currents path completely. This would greatly facilitate manufacturing procedures. The different HP models are tested with similar conditions being kept for each test. Fig.16 compares the eddy current losses in the HP for each model at $50 \mathrm{~Hz}$, showing the effectiveness of the slitting method to reduce the flow of eddy currents. Minimum losses are obviously achieved when the slits open circuit the current flow path completely such as in the model HP2. A combination of one 'complete' slit and two 'non-complete' slits is therefore suggested, resulting in good mechanical robustness, high thermal properties and low eddy current loss.

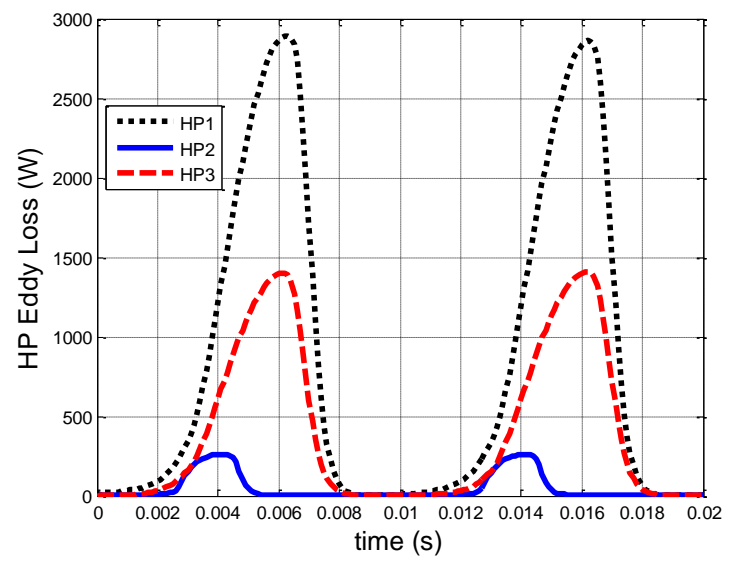

Fig.16 Eddy losses in HP with slitting

\section{EXPERIMENTAL VERIFICATION}

In order to validate and demonstrate the effectiveness of this slot temperature reduction technique, experimental tests were conducted on a purposely built instrumented set-up, which consist of an axially insulated single slot arrangement, its corresponding housing and a cooling arrangement.
Fig.17a shows a photo of the aluminum HP, while Fig.17b shows the pre-formed coils. The HP, the pre-formed coils and the two stator teeth (making up one slot of the TLPM motor) shown in Fig. 18 were assembled into a water-cooled housing. The whole setup was designed with very small geometric tolerances while applying positive interference tolerances where possible. The pre-formed coils and the tubular nature of the setup enable the components of Fig.18 to be assembled under appropriate pressure, thus ensuring a reliable contact between the various components to be achieved. Electrical insulation was achieved by the use of an appropriate thickness of wire insulation and thin slot liner. The use of high performance, ultra-thin, polyimide material as liner could also facilitate assembly procedures in the actual machine. In case of machines where the two coils in the same slot belong to the same phase (i.e. single layer winding) no additional insulation is needed apart from the same slot liner that would be adopted had the HP not been used. The complete instrumented set-up with a number of thermocouples to monitor the temperature distribution is shown in Fig.19. The design details of the experimental setup are shown in Table I.

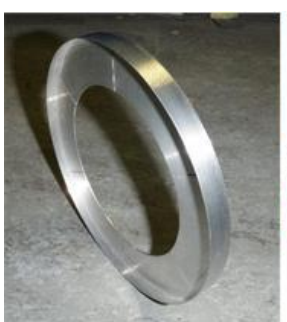

(a)

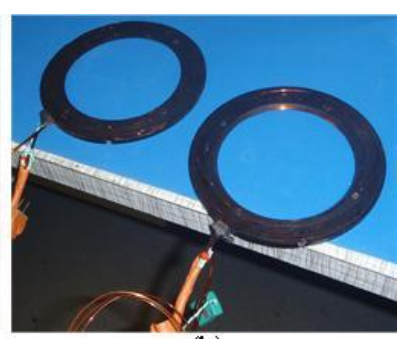

(b)
Fig.17 Heat path and pre-formed coils

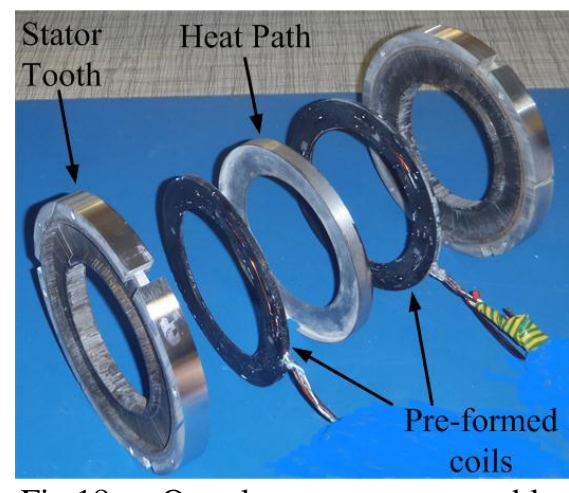

Fig.18 One slot prototype assembly

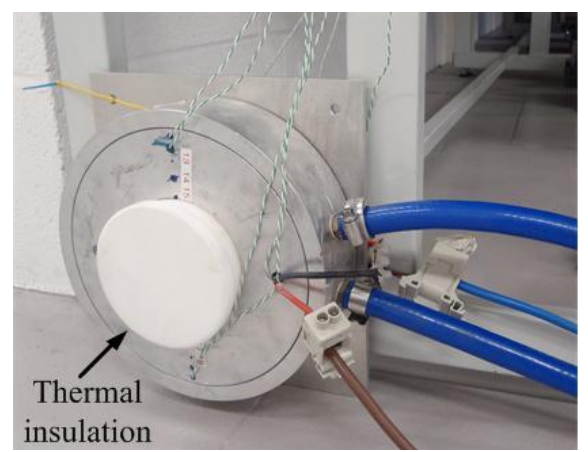

Fig.19 Instrumented set-up 
TABLE I

DATA OF THE EXPERIMENTAL SET-UP
Slot width $T_{s l}$

Slot depth $\left(R_{t}-R_{\text {in }}\right)$

HP thickness $T_{H P 2}$

Slot fill factor $K_{\text {fill }}$

Slot equivalent thermal conductivity $k_{e q}$

Coolant temperature $T_{\text {wat }}$
$11.35 \mathrm{~mm}$

$24.45 \mathrm{~mm}$

$1 \mathrm{~mm}$

0.4963

$4.332 \mathrm{~W} / \mathrm{mK}$

$20^{\circ} \mathrm{C}$
A first experiment without a HP in the slot area was conducted, followed by a similar test with the HP included. The coolant temperature was kept constant at $20^{\circ} \mathrm{C}$. Temperature distribution in the coils was monitored by considering the points in the coils as shown in Fig.20. The point $\mathrm{C}_{\mathrm{c}}$ in Fig.20a indicates the point where maximum temperature is expected to be when the HP is not present. The points C1_HP, C2_HP etc. of Fig.20b are the same points as C1, $\mathrm{C} 2$ etc. but indicate that the HP is present.

As in [13], these tests were done using a DC supply, which as stated in [18] ensures that only the copper joule loss has an effect on the thermal performance. Starting from zero, the DC supply was increased in steps and the temperature distribution recorded for each step. Each measurement was recorded after the appropriate time had been allowed for the temperature to level out to a steady state value.

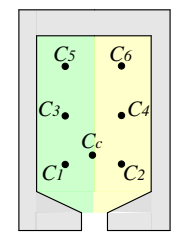

(a)

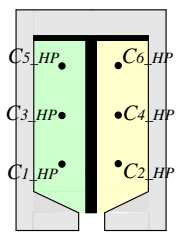

(b)
Fig.20 Temperature measurement points

The temperature results obtained from these two tests are plotted against the copper current density in Fig.21, where for reasons of clarity, only the temperatures of $\mathrm{C}_{1} \_\mathrm{HP}$ and $\mathrm{C}_{2}$ HP are shown, these being the points where temperature is highest. The slight difference between the temperatures of $\mathrm{C} 1 \_\mathrm{HP}$ and $\mathrm{C}_{2} \_\mathrm{HP}$ can be attributed to manufacturing tolerance.

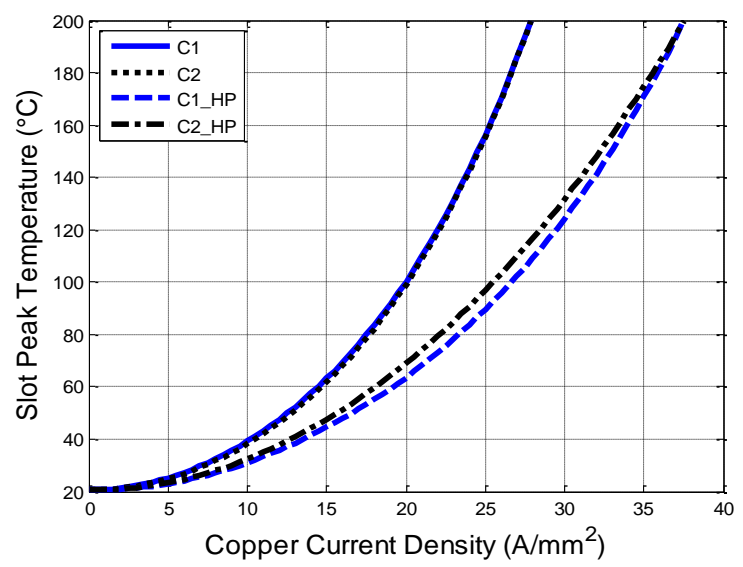

Fig.21 Experimental results
Without the $\mathrm{HP}$, the safe operating temperature of $180^{\circ} \mathrm{C}$ is reached at a $J_{r m s}$ of $26.64 \mathrm{~A} / \mathrm{mm}^{2}$, whereas with the HP included, the same $J_{r m s}$ yields a peak slot temperature of approximately $107.5^{\circ} \mathrm{C}$. This means that for this experimental test a reduction of $\approx 40 \%$ in the slot hot-spot temperature has been achieved, when the HP is included in the slot. The predicted decrease in peak temperature and deviation from the mean when the HP is adopted is thus experimentally validated.

Fig.22 compares the analytical, FE and experimental instrumented set-up results for the point $\mathrm{C} 2$. The slight difference between the models' results and the experimental results is due to manufacturing and experimental tolerances, as well as to the simplifying assumptions taken with regards to the equivalent winding bulk thermal conductivity and coarse discretisation in the resistance thermal model. The analytical model is based on a $k_{e q}$ of $3.756 \mathrm{~W} / \mathrm{mK}$ as calculated using (17), whereas the experimental $k_{e q}$ was found to be $4.332 \mathrm{~W} / \mathrm{mK}$. An improved agreement between the resistance network and experimental results can be achieved, if an adjusted $k_{e q}$ of $4.87 \mathrm{~W} / \mathrm{mK}$ for the analytical model is used.

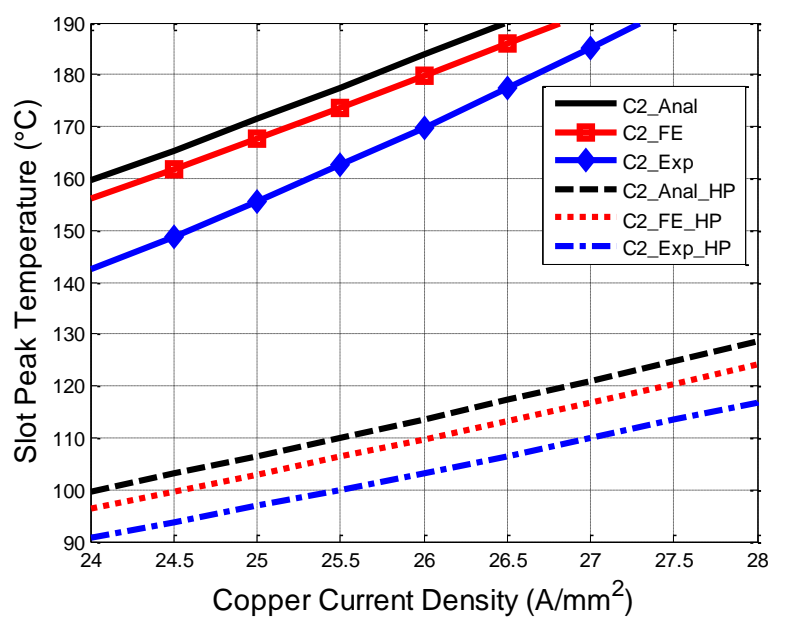

Fig.22 Comparing analytical, FE and experimental results

\section{CONCLUSION}

A lumped parameter thermal network to model a tooth-slot section of a water cooled tubular motor has been presented. The model was used to investigate a thermal improvement technique for reducing the hot-spot temperature in the phase windings of electrical machines. Results from the model were compared to FE and experimental results, showing reasonable agreement between all of the results. This confirms the adequateness of the analytical model and more importantly the thermal improvement technique.

It has been shown in this paper that by this technique a reduction of approximately $40 \%$ in the slot hot-spot temperature can be achieved for the same current loading. Considering appropriate electro-magnetic design, this gives the machine designer the possibility to design his machines for higher current densities and consequently a higher force/torque-to-unit-mass ratio. 


\section{APPENDIX}

Table II compares the thermal resistances of the TLPM motor before and after the insertion of the HP, calculated using (1-11), (16) and (19-23), using the same parameters as used to obtain the results of Fig.8 and Fig.9.

TABLE II

COMPARISON OF THERMAL RESISTANCES

\begin{tabular}{|c|c|c|}
\hline & $\begin{array}{c}\text { Without HP } \\
(\mathrm{W} / \mathrm{mK})\end{array}$ & $\begin{array}{c}\text { With HP } \\
(\mathrm{W} / \mathrm{mK})\end{array}$ \\
\hline$R_{I}$ & 0.1358 & 0.1215 \\
\hline$R_{2}$ & 2.034 & $R_{2}=1.995 \quad R_{H P 2}=0.12$ \\
\hline$R_{3}$ & 0.0679 & 0.06075 \\
\hline$R_{4}$ & 1.455 & $R_{4}=1.455 R_{H P I}=0.0899$ \\
\hline$R_{5}$ & 0.154 & 0.154 \\
\hline$R_{6}$ & 0.0058 & 0.0058 \\
\hline$R_{7}$ & 0.272 & 0.272 \\
\hline$R_{8}$ & 0.279 & 0.279 \\
\hline$R_{9}$ & 0.686 & $R_{H P 3}=0.687$ \\
\hline$R_{I 0}$ & 0.038 & 0.038 \\
\hline$R_{11}$ & 0.015 & 0.015 \\
\hline$R_{I 2}$ & 0.0129 & 0.0129 \\
\hline
\end{tabular}

\section{REFERENCES}

[1] A. Boglietti, A. Cavagnino, D. Staton, M. Shanel, M. Mueller and C. Mejuto, "Evolution and modern approaches for thermal analysis of electrical machines," IEEE Trans. on Industrial Electronics, vol. 56, issue 3, pp. 871-882, 2009.

[2] C. Gerada, K. Bradley, C. Whitley and G. Towers, "High torque density PM machines for high performance operation," in Proc. $33^{\text {rd }}$ Annu. Conf. of the IEEE Industrial Electronics Society , IECON 2007, Taipei, Taiwan, 2007, pp. 210-215.

[3] T. Raminosoa, C. Gerada and M. Galea, "Design considerations for a fault tolerant flux switching permanent magnet machine," IEEE Trans. on Industrial Electronics, vol. 58, no.7, pp. 2818-2825, 2011.

[4] A. Hughes, Electric motors and drives: fundamentals, types and applications. 3rd ed., Newnes, Oxford, 2006.

[5] L. Kung, U. Bikle, O. Popp and R. Jakoby, "Improvement of the cooling performance of symmetrically self-ventilated induction machines in the 2-15 MW range," in Proc. of the IEEE International Electrical Machines and Drives Conf., IEMDC 2001, 2001, pp. 673-680.

[6] A. Boglietti, A. Cavagnino, M. Lazzari and A. Pastorelli, "A simplified thermal model for variable speed self-cooled industrial induction motor," IEEE Trans. on Ind. App., vol. 39, issue 4, pp. 945-952, 2003.

[7] G. M. Gilson, T. Raminosoa, S. J. Pickering, C. Gerada and D. B. Hann, "A combined electromagnetic and thermal optimization of an aerospace electric motor," in Proc. of the XIX International Conf. on Electrical Machines, ICEM 2010, Rome, Italy, Sept. 2010, pp. 1-7.

[8] B. Yazicioglu and H. Yuncu, " A correlation for optimum fin spacing of vertically-based rectangular fin arrays subjected to natural convection heat transfer," Journal of Therm. Science and Tech., pp. 99-105, 2009.

[9] S. Pickering, F. Thovex, P. Wheeler and K. Bradley, "Thermal design of an integrated motor drive," in Proc. of the $32^{\text {nd }}$ Annual Conf. of the IEEE Industrial Electronics, IECON 2006, Nov. 2006, pp. 4794-4799.

[10] J. Mugglestone, S. Pickering and D. Lampard, "Effect of geometric changes on the flow and heat transfer in the end region of a TEFC induction motor," in Proc. of the $9^{\text {th }}$ International Conf. on Electrical Machines and Drives, Sept. 1999, pp. 40-44.

[11] C. Kral, A. Haumer and T. Bauml, "Thermal model and behavior of a totally-enclosed-water-cooled squirrel-cage induction machine for traction applications," IEEE Trans. on Industrial Electronics, vol. 55, issue 10, pp. 3555-3565, 2008.

[12] B. Funieru and A. Binder, "Thermal design of a permanent magnet motor used for gearless railway traction," in Proc. $34^{\text {th }}$ Annu. Conf. of the IEEE Ind. Elect. Society, IECON 2008, Nov. 2008, pp. 2061-2066.

[13] M. Galea, C. Gerada, T. Raminosoa and P. Wheeler, "Design of a high force density tubular permanent magnet motor," in Proc. of the XIX Inter. Conf. on Elect. Machines, ICEM 2010, Italy, Sept. 2010, pp. 1-6.
[14] K. M. Takami and J. Mahmoudi, "A new apparatus for mitigating the hot spot problem in large power transformers using the ANTS algorithm," in Proc. of the Power Engineering Society Conference and Exposition in Africa, PowerAfrica'07, South Africa, July 2007, pp. 1-8.

[15] C. H. Holley and H. D. Taylor, "Direct cooling of turbine-generator field windings," American Institute of Electrical Engineers, Trans. on Power Apparatus and Systems, Part III-A, vol. 73, issue 1, pp. 542-550, 1954.

[16] N. Bianchi, S. Bolognani, D. D. Corte and F. Tonel, "Tubular Linear Permanent Magnet Motors: An overall comparison," IEEE Trans. on Industry Applications, vol. 39, no. 2, pp. 466-475, 2003.

[17] R. Wrobel, P. H. Mellor, N. McNeill and D. A. Staton, "Thermal performance of an open-slot modular-wound machine with external rotor," IEEE Trans. Energy Conv., vol. 25, issue 2, pp. 403-411, 2010.

[18] A. Boglietti, A. Cavagnino, D. Staton, M. Popescu, C. Cossar and M. McGilp, "End space heat transfer coefficient determination for different induction motor enclosure types," IEEE Trans. on Industry Applications, vol. 45, issue 3, pp. 929-937, May-June 2009.

[19] C. Micallef, S. Pickering, K. Simmons and K. Bradley, "An alternative cooling arrangement for the end region of a totally enclosed fan cooled (TEFC) induction motor," in Proc. of the $4^{\text {th }}$ IET Conf. on Power Electronics, Machines and Drives, PEMD 2008, pp. 305-309, 2008.

[20] A. Boglietti, A. Cavagnino and D. A. Staton, "Determination of critical parameters in electrical machine thermal models," IEEE Trans. on Industry Applications, vol. 44, issue 4, pp. 1150-1159, 2008.

[21] P. H. Mellor, D. Roberts, and D. R. Turner, "Lumped parameter thermal model for electrical machines of TEFC design," IEE Proceedings B, Electric Power Applications, vol. 138, pp. 205-218, 1991.

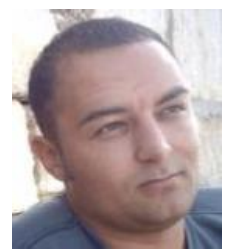

Michael Galea received his B.Eng (Hons) and M.Sc degrees in electrical engineering from the University of Malta in 2007 and 2009, respectively. He is currently working towards his $\mathrm{PhD}$ in electro-magnetic and electrical machine design with the Power Electronics, Machines and Control Group at the University of Nottingham, UK. His main research interests are unconventional linear motors and electrical machine thermal improvements.

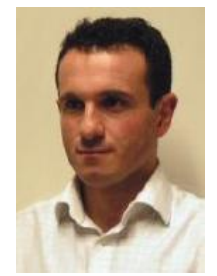

Chris Gerada (M'05) obtained his PhD in Numerical Modelling of Electrical Machines from the University of Nottingham, England in 2005. He subsequently worked as a researcher at Nottingham on high performance electrical drives and on the design and modelling of electromagnetic actuators for aerospace applications. He is currently an Associate Professor within the PEMC research group at Nottingham. He is also the project manager of the GE Aviation Strategic Partnership and his research interests include high performance electric drives and machines.

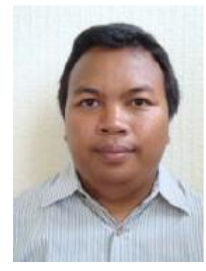

Tsarafidy Raminosoa (M'10) received the Ph.D. degree in Electrical Engineering from the National Polytechnic Institute of Lorraine, Nancy, France, in 2006. From 2006 to 2008, he was a Research Assistant with the Department of Electrical Engineering and Control Systems, University of Technology of Belfort-Montbeliard, Belfort, France. From 2008 to 2010, he was a Research Fellow with the Power Electronics, Machines and Control Research Group, University of Nottingham, Nottingham, U.K. In 2011, he joined the Electrical Machines Laboratory at GE Global Research, Niskayuna, U.S, where he is currently an Electrical Engineer. His research interests include electric machine design and modelling.

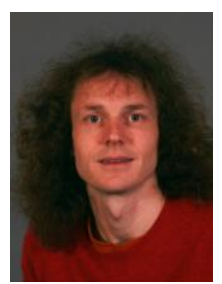

Patrick Wheeler (M'00) received his BEng (Hons) in 1990 from the University of Bristol, UK. He received his $\mathrm{PhD}$ degree in Electrical Engineering for his work on Matrix Converters from the University of Bristol, UK, in 1994. In 1993 he moved to the University of Nottingham and worked as a research assistant in the Department of Electrical and Electronic Engineering. In 1996 he became a Lecturer in the Power Electronics, Machines and Control Group at the University of Nottingham, UK. Since January 2008 he has been a Full Professor in the same research group. His research interests are in power conversion, Energy and More Electric Aircraft technology. 